\title{
Dimensi Etis Iklan, Studi Kasus Pada Iklan Sampo Anti Dandruff dan Iklan Belanja Online di Media Televisi
}

*Ni Luh Putu Ratna Suandari ${ }^{1}$, Fajri Rahma Pratiwi'2, Handriyotopo ${ }^{3}$

Fakultas Seni Rupa dan Desain, Institut Seni Indonesia Surakarta ${ }^{1,2,3}$

Artikel History

Dikirim: 5 Sept. 2021

Revisi : 25 Okto. 2021

Diterima: 20 Nop. 2021

\begin{abstract}
The ethical dimension related to advertising ethics towards advertisements broadcast on television media often violates the rules. The case study of the Pantene advertisement version of "Anti Drandruf Ads" played by Anggun C. Sasmi and the online shop version of the Shopee advertisement with Korean artist Black Pink were criticized by KPI regarding broadcast hours and their effect on children. The perspective of this research is the ethical dimension by Kevin Johnston and Tanya Robertson, with descriptive qualitative research methods interpretive analysis of advertising criticism. The evaluative finding of advertising art criticism in this study is that the morality of advertising ethics by comparing it with other products orally is still considered reasonable but the advertising dimension is negative. In the case of the Shopee advertisement with the Black Pink artist, it contains elements of sexism that should not be consumed by children.
\end{abstract}

Keywords: ethical dimensions of advertising, negative advertising, sexism

\begin{abstract}
Abstrak
Dimensi etis terkait etika pariwara atau iklan yang ditayangkan di media televisi seringkali melanggar aturan. Studi kasus iklan Pantene versi "Iklan Anti Drandruf" yang diperankan oleh Anggun C. Sasmi dan iklan Shopee versi toko online dengan artis Korea Black Pink di kritik oleh KPI terkait jam tayang dan pengaruhnya terhadap anak-anak. Perspektif kajiannya adalah dimensi etis oleh Kevin Johnston dan Tanya Robertson, dengan metode penelitian kualitatif deskriptif interpretative analisis kritik iklan. Temuan evaluatif kritik seni iklan dalam penelitian ini adalah etika moralitas iklan dengan membandingan dengan produk lain secara verbal masih dianggap wajar namun dimensi iklannya negatif. Pada kasus iklan Shopee dengan artis Black Pink mengandung unsur seksisme yang semestinya tidak dikonsumsi anak-anak.
\end{abstract}

Kata kunci: dimensi etis iklan, iklan negatif, seksisme 


\section{PENGANTAR}

Dewasa ini perkembangan teknologi dan komunikasi mengalami kemajuan yang begitu pesat. Hal ini membuat perusahaan harus berpikir secara kreatif dan inovatif dalam mengembangkan strategi pemasaran. Salah satu bentuk pemasaran yang dilakukan oleh perusahaan dalam memasarkan produknya yaitu dengan menggunakan iklan. Menurut Kottler (2005) mengatakan bahwa iklan merupakan bentuk presentasi non-personal dan promosi suatu gagasan, barang atau jasa yang dibiayai oleh sponsor yang telah teridentifikasi (Putra, 2014). Selain itu, Morissan (2010) mengatakan bahwa iklan merupakan salah satu bentuk promosi yang paling dikenal karena memiliki jangkauan yang luas (Rizaldi, 2017). Oleh karena itu, perusahaan berkompetensi dalam membuat iklan yang menarik agar konsumen tertarik dengan produk yang ditawarkan.

Namun, hal ini membuat persaingan antar perusahaan menjadi tidak sehat. Dimana beberapa iklan dibuat melanggar etika periklanan untuk mendapatkan simpati dari konsumen agar tertarik dengan produk yang dipasarkan. Kegiatan tersebut merupakan tindakan yang ilegal dan tidak etis, karena menyesatkan konsumen mengenai produk (Subroto, 2011). Hal ini didukung oleh pendapat Piliang (2010) dalam Jurnal Imaji (2014) yang menyatakan bahwa perkembangan periklanan saat ini menimbulkan berbagai permasalahan sosial dan budaya di masyarakat, dimana hal ini berkaitan dengan tanda (sign) dalam periklanan, citra ( gambar). yang ditampilkan, informasi yang disampaikan, makna yang diperoleh, serta pengaruh persepsi, pemahaman, perilaku terhadap masyarakat dan apakah iklan tersebut ditampilkan secara nyata atau hanya sebagai topeng dari kenyataan.

Etika dalam periklanan di Indonesia memang terkadang masih terdapat kecolongan oleh lembaga yang menangani sensor dan semacamnya. Maka lahirlah suatu kritik periklanan yang membahas beberapa sisi negatif yang terdapat dari iklan. Karena tujuan utama iklan tersebut untuk menginformasikan suatu produk barang ataupun jasa agar mendapat citra yang baik di mata para konsumennya. Namun, jalan yang dipilih oleh produsen seiring berjalannya waktu malah menyimpang dari etika dan norma yang diterapkan di Indonesia. 
Menurut Setyowati Subroto, periklanan sudah menjadi bagian tak terpisahkan dari dunia bisnis dan selalu mendapat perhatian masyarakat luas. Namun, ada kekhawatiran bahwa iklan yang dikomunikasikan setiap hari melalui media massa umumnya tidak mendidik untuk menyebarkan selera rendah. Dari segi moral, iklan tidak memiliki nilai informatif, karena semata-mata untuk kepentingan produsen. (Subroto, 2011). Periklanan juga dipandang sebagai salah satu media yang paling efektif dalam mengkomunikasikan suatu produk dan jasa. Selain itu iklan dibuat oleh masing-masing perusahaan untuk membuat konsumen tertarik dan berharap tidak berpaling dari perusahaan lain yang sejenis, oleh karena itu perusahaan harus membuat iklan yang semenarik mungkin. (Astuti, 2015)

Dilihat dari berbagai cara yang digunakan oleh perusahaan dalam mempromosikan sesuatu demi menaikkan sebuah merek yang dipasarkan. Membuat penulis tertarik untuk menganalisa iklan kecantikan, yaitu iklan shampo Pantene. Dimana iklan shampo mengiklankan bagian terpenting dari perempuan yaitu rambut. Rambut merupakan salah satu aset kecantikan yang dimiliki oleh perempuan dimana sangat berpengaruh dalam meningkatkan kepercayaan diri (Zulkifli et al., 2019). Hal ini membuat perempuan berhati-hati dalam memilih produk shampo. Kaum perempuan ingin mencari produk yang terbaik agar rambut yang dimilikinya tampil sehat dan indah. Di lain pihak objek iklan dalam televisi pada salah satu iklan yang menyimpang hingga berdampak negatif pada tumbuh kembang anak adalah iklan aplikasi belanja online Shopee yang dibintangi oleh girlband asal negeri gingseng yaitu Blank Pink. Pada penayangan iklan tersebut terlihat bahwa girlband memakai baju yang dianggap terlalu seksi termasuk kedalam seksualitas dalam iklan.

\section{Literatur Review dan Landasan Teori}

Rahmi DP dan Handriyotopo mendeskripsikan secara kritis atas bias gender dan seksisme untuk mengetahui pesan-pesan, menguraikan citra yang disampaikan melalui audio-visual iklan dengan mengkomparsikan budaya gender di Indonesia pada penelitian iklan Shampoo Pantene "Labels Against Women." Penelitiannya dilakukan dengan menggunakan metode penelitian kualitatif deskriptif melalui 
semiotika intertekstualitas analisis Julia Kristeva's. Penelitian ini adalah jenis penelitian teks untuk memahami sistem tanda dalam iklan, dengan metode analisis pada frame tiap adegan untuk menggambarkan iklan secara keseluruhan, mendeskripsikan tanda yang mengandung unsur budaya gender dan memaknainya. Temuan penelitian dengan pendekatan gender dan analisis semiotika Julia Kristeva adalah iklan Pantene ini mengkampanyekan kesetaraan gender, dan menentukan wanita pekerja sebagai konsumen. (Rahmi DP dan Handriyotopo, 2018) Namun dalam penelitian ini berbeda dengan penelitian dari Rahmi DP dan Handriyotopo yang menggunakan pendekatan kritik iklan. Perspektif kritik iklan adalah dari sudut dimensi etis iklan dengan objek material Iklan Shampo Pantene dan iklan Shopee yang menampilkan artis Korea. Temuan diharapkan bukan persoalan feminisme dalam kontek gender akan tetapi etika iklan terhadap produk yang disampaikan ke khalayak konsumennya apakah berkorelasi negatif atau tidak kaitannya dengan budaya kesopanan ketimuran khususnya di Indonesia. Dengan demikian penelitian ini berbeda dari perspektif kajiannya meskipun sama-sama objek materialnya iklan di media televisi.

Kondisi tersebut merupakan tantangan bagi perusahaan produk shampo dalam memasarkan produk shampo. Selain itu, tantangan yang lainnya adalah menarik kepercayaan kaum perempuan untuk menggunakan produk shampo Pantene. Tidak hanya itu saja, banyak produk shampo yang memiliki keunggulan masing-masing dan itu termasuk tantangan bagi perusahaan. Hal ini membuat perusahaan produk shampo Pantene perlu membuat iklan yang menarik. Mendapatkan unsur menarik dalam iklan Pantene, perusahaan Pantene harus menggunakan etika periklanan karena etika periklanan berfungsi untuk melindungi konsumen. Dari fenomena di atas maka menganalisa etika periklanan yang digunakan oleh perusahaan Pantene dalam iklan produk shampo Pantene. Demikian pula pada aspek etis iklan dari Shopee yang menampilkan artis Korea yang cukup seksi, dimana menurut Kevin Johnston menyatakan daya tarik seksual telah digunakan untuk menjual produk sejak lama. Hal ini memang tidak melanggar aturan etika saat menempatkan model wanita yang menarik dalam sebuah iklan. Namun, penggambaran terus menerus sebagaimana dikutip dalam pernyataan Kevin 
Johnston tentang wanita sebagai objek seksualitas, maka jika pada jam tayangan tidak tepat dapat ditonton oleh anak-anak akan berdampak negatif (Handriyotopo, 2021)

Iklan dibuat tidak hanya untuk menjual sebuah produk, namun iklan juga membentuk image, values, dan konsep produk (Kumalaningtyas and Sadasri, 2018). Hal tersebut mampu membangun citra sebuah produk yang akan diiklankan. Namun, iklan yang baik adalah iklan yang mampu menyampaikan kebenaran produk kepada konsumen (Handriyotopo, 2021). Pada saat tertentu, iklan akan mengabaikan etika periklanan demi meningkatkan keuntungan. Hal ini didukung oleh Kevin Johnston yang menyatakan bahwa terkadang iklan akan tergoda untuk membengkokkan kebenaran mengenai perusahaan, produk, atau jasa. Tetapi keuntungan yang didapat jika menyebarkan kebenaran bisa menjadi kerugian pelanggan karena mulai timbul rasa tidak percaya terhadap perusahaan pengiklan karena menggunakan iklan yang menipu (Handriyotopo, 2021). Perspektif dimensi iklan etis dan kaitannya dengan analisis pada studi kasus iklan di atas maka iklan dapat saja ditayangkan ditelevisi namun seringkali masih mengandung unsur-unsur negatif seperti yang diungkapkan oleh Kevin Johnston sebagai berikut;

1. Mengandung pembohongan tentang fitur atau manfaat produk.

2. Menggunakan streotip rasial dan seksual

3. Mempromosikan jenis yang ilegal seperti rokok alcohol dan makanan berlemak pada anak anak

4. Sengaja mendistorsikan kebenaran

5. Menggunakan streotip rasial dan seksual

6. Mempromosikan jenis yang illegal seperti rokok alcohol dan makanan berlemak pada anak-anak

7. Sengaja mendistorsikebenaran

Melihat hal tersebut, aspek kritik iklan disini adalah melakukan evaluasi yang mempertimbangkan baik buruk terhadap hasil karya terhadap dua objek material sebagai studi kasus iklan di media televisi atas teks-teks yang dimunculkan dalam iklan tersebut sebagai karya seni kreatif iklan. Menurut kbbi online, 
Kritik/kri tik/ $n$ kecaman atau tanggapan, kadang-kadang disertai uraian dan pertimbangan baik buruk terhadap suatu hasil karya, pendapat, dan sebagainya.

\section{Metode}

Pendekatan metodelogi yang digunakan adalah penelitian kualitatif deskriptif interpretative atas dimensi etis iklan dengan analisis kritik. Penelitian kualitatif dipandang mampu untuk menemukan makna secara objektif atas objek material yang dikaji atau di analisis kritik iklan dengan perspektif dimensi etis iklan dari Kevin Johnston dan Tanya Robertson. Selain teori yang dikemukakan oleh Kevin Johnston, kritik iklan negatif juga dipaparkan oleh Tanya Robertson pada aspek hormati tanggung jawab sosial karena efek dari tontonan yang kurang etis dapat menimbulkan efek yang negatif bagi tumbuh kembang anak. Objek material sebagai purposive sampling dalam penelitian ini adalah iklan adalah iklan Pantene Anti Dandruf yang diperankan oleh Anggun C. Sasmi dan iklan Shopee yang menampilkan artis Korea Black Pink.

\section{PEMBAHASAN}

\section{Analisis Kritik Iklan Pantene Versi Anti Dandruff}

Pembengkokan kebenaran terhadap iklan, secara tidak sengaja digunakan oleh iklan shampoo Pantene "Anggun Memilih Pantene Anti Dandruff" dimana iklan tersebut memaparkan manfaat jika menggunakan shampo tersebut rambut tidak akan ketombe dan tidak akan rontok (Pantene, 2016). Manfaat tersebut dijelaskan dengan metode testimoni yang dirasakan oleh brand ambassador-nya yaitu Anggun C. Sasmi. Hal ini membuat konsumen percaya jika produk tersebut mempunyai khasiat yang sangat bagus. Selain itu, bagi konsumen yang mengidolakan Anggun, secara otomatis mereka akan mencoba shampo yang digunakan oleh idolanya tersebut. 


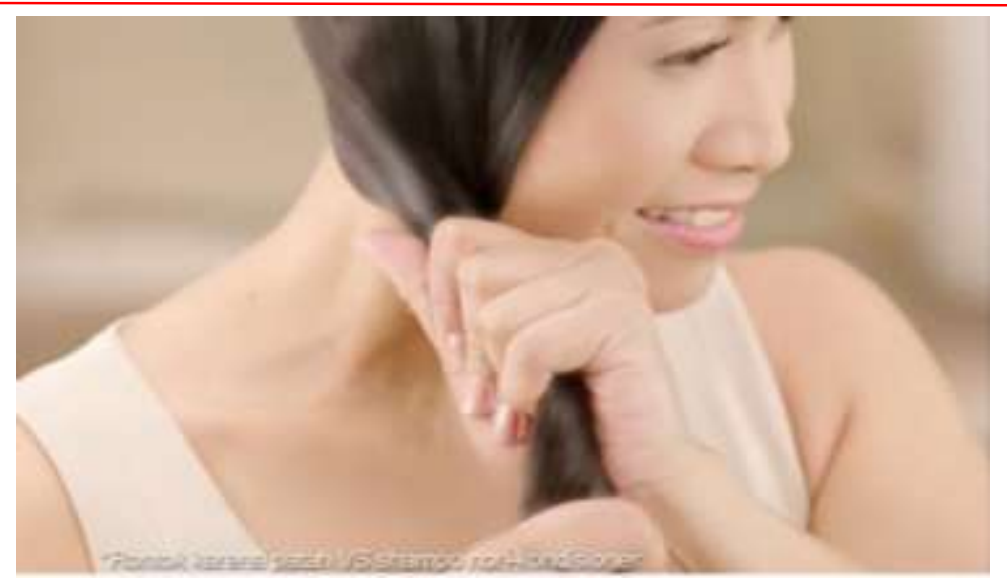

Gambar 1. Iklan Pantene Anti Dandruft yang dibintangi Anggun C.Sasmi (sumber: Youtube.com)

Selain itu, iklan ini mengandung etika periklanan negatif, yang dimana etika periklanan negatif ini menggambarkan pesaing secara negatif dalam upaya membuat iklan terlihat lebih unggul. Hal tersebut tampak saat Anggun C. Sasmi mengatakan "Dulu pernah mencoba shampo lain, tapi ketombe dan rontok balik lagi, aku sama Pantene saja, rambutku ga ketombean lagi dan ga rontok lagi" (Pantene, 2016). Pendapat tersebut seakan-akan menjatuhkan merek produk shampo yang lainnya. Namun, etika periklanan negatif masih dianggap tetap etis jika masih mempertahankan standar moral tertentu. Hal ini didukung oleh pendapat dari Tanya Robertson dalam Kritik Iklan Handriyotopo (2021) yang menyatakan bahwa iklan negatif menggambarkan pesaing secara negatif dalam upaya membuat pengiklan terlihat lebih baik, jenis iklan ini digunakan di dunia politik dan dunia bisnis, walaupun dianggap praktik ini tidak etis dan tidak bertanggung jawab tetapi iklan negatif tetap dianggap etis jika mempertahankan standar moral tertentu. Untuk iklan Pantene "Anggun Memilih Pantene Anti Dandruff', walaupun merendahkan produk shampo lain tetapi tetap mempertahankan standar moral yaitu tidak menyebutkan merek produk shampo secara spesifik. Iklan ini dianggap iklan negatif yang etis karena iklan ini menunjukkan kekurangan yang jelas terhadap produk pesaing saat membandingkan produk shampo Pantene dengan produk shampo lainnya. Oleh karena itu iklan ini mengandung etika periklanan yang dapat dikatakan berada di posisi negatif. 


\section{Analisis Kritik Iklan Shopee Versi Black Pink}

Iklan medium televisi termasuk memiliki dampak yang besar pada pertumbungan karakter anak dan bagaimana anak berpakaian pada hakikatnya anak di bawah umur masih belum mengerti dan membedakan mana yang baik dan yang buruk. Maka dari itu lembaga KPI (Komisi Penyiaran Indonesia) telah melayangkan peringatan keras pada 11 stasiun televisi yang menayangkan iklan Shopee Black Pink siaran iklan dan program acara tersebut dinilai tidak memperhatikan ketentuan tentang penghormatan terhadap norma kesopanan yang semestinya ditayangkan saat bukan jam belajar anak. (http:/ / www.kpi.go.id/, 2018)

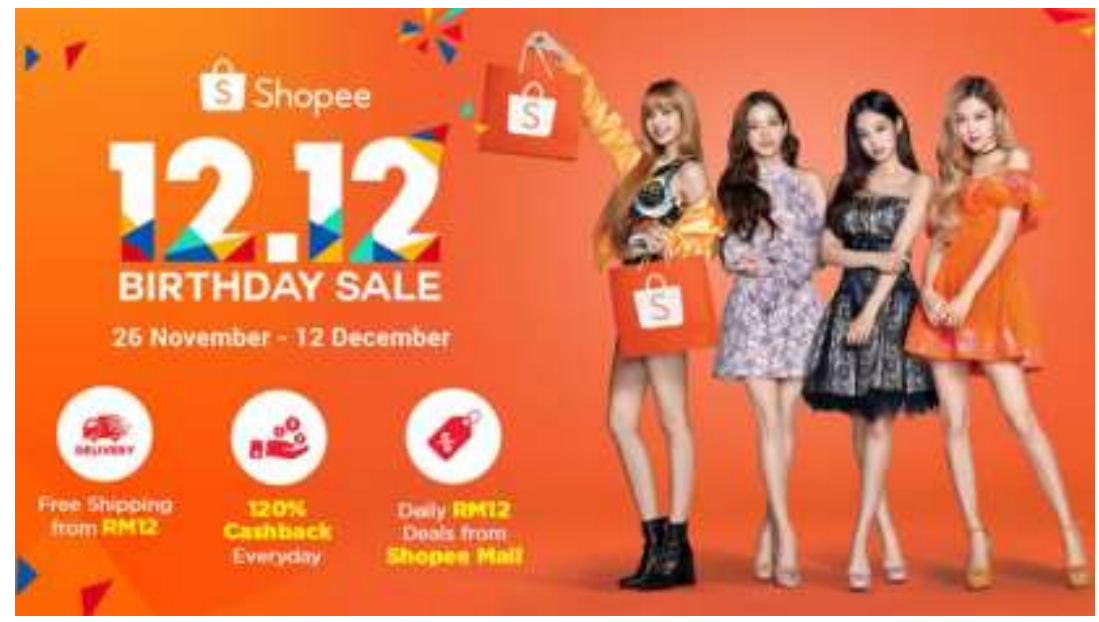

Gambar 2. Iklan Shopee 12.12 Birthday Sale yang dibintangi Blank Pink. (Sumber : https:/ / Fin.Co.Id, 2018)

Analisis Kritik dengan pendekatan Etika iklan terhadap Iklan Shopee Black Pink melalui Teori Kevin Johnston sebagai berikut; Stereotipe Rasial, menciptakan sudut pandang feminisme bahwa wanita sebagai objek dalam iklan. Representasi kebebasan seorang wanita dalam iklan, menantang pemikiran kepada audiens iklan televisi tersebut menimbulkan kesan patriarki atas keindahan tubuh perempuan sebagai objek. (Anindya, Annisa, 2019). Target pada Anak-Anak, iklan ini ditayangkan ke 11 stasiun televisi dan pada waktu yang dapat dilihat oleh anak-anak dengan visual yang tidak etis dan menimbulkan efek negatif bagi tumbuh kembang anak. Seksualitas dalam iklan, penggambaran terus-menerus tentang wanita sebagai objek seksual 
kaum pria sebagai pengejarnya akan menampakkan tidak kenyamanan yang akan berimbas pada usaha.

\section{KESIMPULAN}

Berdasarkan analisis di atas terhadap iklan sampo dari produk Pantene yang dibuat juga harus sesuai dengan etika periklanan, karena etika periklanan merupakan sebuah acuan agar konsumen tidak merasa dirugikan. Iklan Pantene "Anggun Memilih Pantene Anti Dandruff' ini mengandung etika periklanan negative. Dimana iklan ini menjatuhkan produk pesaing secara implisit namun menunjukkan kekurangan produk lain secara jelas hal ini membuat adil dan masih dianggap etis. Selain itu, iklan ini juga tidak menjatuhkan merek shampo secara spesifik.

Terkait dengan iklan Shopee maka menurut perspektif Tanya Robertson, iklan negatif menggambarkan pesaing secara negatif dalam upaya untuk membuat pengiklan terlihat lebih baik. Jenis iklan ini dapat digunakan di arena politik maupun dunia bisnis. Meskipun Sebagian besar manganggap praktik ini tidak etis dan tidak bertanggungjawab, iklan negatif dapat tetap etis selama bisnisnya mempertahankan standar moral tertentu. Dengan demikian pada iklan yang menampilkan artis Korea Black Pink pada medium iklan televisi di Indonesia dan berdasarkan etika moral dari KPI dan sudut pandang Kevin Johnston adalah standar moralnya ketika budaya cara berpakaian yang menunjukkan seksisme tidak cukup baik dan dianggap negatif jika yang melihat anak-anak yang belum cukup umur atau dewasa.

Iklan yang dapat menimbulkan dampak negatif atas tumbuh kembangnya anak maka menurut KPI pada tayangan iklan haruslah memperhatikan kepentingan dan perlindungan anak serta remaja. Hal ini tertuang dalam Pasal 14 ayat 2 P3 dan Pasal 15 ayat 1 SPS dimana pada Pasal 14 ayat 2 menyebutkan bahwa lembaga penyiaran wajib memperhatikan kepentingan anak dalam setiap aspek produksi siaran. Hal inilah seringkali para kreator lupa akan pemahaman undang-undangnya dan ketika disiarkan ke media televisi akan mendapatkan teguran. Hal ini mestinya dapat diterima sebagai kritik. Dan tentu saja insan kreatif untuk membuat karya iklan lebih kreatif kedepannya, sehingga tidak melanggar etika pariwara di Indonesia. 


\section{DAFTAR PUSTAKA}

Anindya, Annisa, D. (2019). Feminisme dan Stereotip Gender dalam Iklan Produk Kecantikan. JESS (Journal of Education on Social Science), 3(2), 113. https://doi.org/10.24036/jess/vol3-iss2/159

Astuti, M. (2015). Peranan Media Periklanan Dalam Pembelian Mobil Truk Pada PT. ASTRA International Tbk. Auto 2000 Cabang Plaju Palembang. 1-13. http:/ / eprints.polsri.ac.id/726/

Fathurrohman (2018) Iklan Shopee Berdampak Negatif pada Pertumbuhan Anak. https:/ / fin.co.id/2018/12/13/iklan-shopee-berdampak-negatif-padapertumbuhan-anak/

Handriyotopo (2021) 'Dimensi Etis dari Iklan'. Available at: file:/ / D:/download new/Kritik Iklan 06 (1).pdf.

Rahmi Dyah Pratiwi, Handriyotopo (2018) Di Balik Citra Iklan Shampoo Pantene (Makna Bias Gender pada Iklan Pantene versi Labels Against Women di Televisi).Texture, Vol 1, No 2 (2018) , https:/ /jurnal.isiska.ac.id/index.php/TXT/issue/view/296/showToc

Kumalaningtyas, N. and Sadasri, L. M. (2018) 'Citra Tubuh Positif Perempuan Dalam Iklan Video Digital (Studi Femvertising Pada Iklan Dove Real Beauty)', Diakom: Jurnal Media dan Komunikasi, 1(2), pp. 62-73. doi: 10.17933/diakom.v1i2.19.

Pantene (2016) Anggun Memilih Pantene Anti Dandruff. Indonesia. Available at: https://www.youtube.com/watch?v=yleANQkKEHQ.

Putra, A. T. (2014) Deskripsi Iklan Nissin Lemonia Periode 2013 Pada Media Televisi. Universitas Pancasila. Available at: http://dosen.univpancasila.ac.id/dosenfile/7009230033149941985007July2017. pdf.

Rizaldi, A. (2017) Pengaruh Daya Tarik Iklan Dan Celebrity Endorser Terhadap Minat Beli Cosmetic Wardah. Universitas Islam Negeri. Available at: http:/ / repository.uinjkt.ac.id/dspace/bitstream/123456789/37465/1/ajie rizaldi-fitk.pdf.

RG. (2018). KPI Minta Stasiun TV Hentikan Iklan "Shopee Blackpink" di Jam Anak http://www.kpi.go.id/index.php/id/umum/38-dalam-negeri/34846-kpiminta-stasiun-tv-hentikan-iklan-shopee-blackpink

Subroto, S. (2011) 'Etika periklanan'. Available at: file:// / D:/ download new/213Article Text-419-1-10-20131024.pdf.

Zulkifli et al. (2019) 'Pengaruh Periklanan Islami Terhadap Keputusan Pembelian Produk Shampoo Hijab Sunsilk Clean And Fresh pada Mahasiswi Universitas Islam Riau', Jounal of Management adn Bussines (JOMB), 1, pp. 59-73. doi: https://doi.org/10.31539/jomb.v1i1.604. 